\title{
Didactic Reform: Organising Learning Projects on Distance and Applications in Taxicab Geometry for Students Specialising in Mathematics
}

\author{
Chu Cam Tho ${ }^{1, *}$, Tran Thi Ha Phuong ${ }^{2}$ \\ ${ }^{I}$ Vietnam Institute of Educational Sciences \\ ${ }^{2}$ Bac Giang Specialized Upper Secondary School, \\ Hoang Van Thu Street, Bac Giang City, Bac Giang, Vietnam \\ Received 12 January 2016 \\ Revised 15 March 2016; Accepted 22 June 2017
}

\begin{abstract}
In the early $20^{\text {th }}$ century, Hermann Minkowski (1864-1909) proposed an idea about a new metric, one of many metrics of non-Euclidean geometry that he developed called Taxicab geometry. The purpose of this paper is to design activities so that students can construct the concept of distance and realise practical applications of Taxicab geometry.
\end{abstract}

Keywords: Didactic reform, taxicab geometry, project-based learning.

\section{Introduction}

One of the ways to gain a deeper understanding of Euclidean geometry is to examine its relation to other non-Euclidean geometries. The selected non-Euclidean geometry which compare with Euclidean geometry needs satisfying the following conditions: (1) it must be similar to Euclidean geometry in terms of structure; (2) it must have practical applications; and (3) it must be suitable in terms of knowledge for high school students who have gained a foundational understanding of Euclidean geometry. Taxicab geometry first put forward by Minkowski satisfying the three mentioned conditions above [1, p12]. Minkowski constructed many spaces with various formulas to calculate distance for the purpose of completing

\footnotetext{
Corresponding author. Tel.: 983380718.

Email: chucamtho1911@gmail.com

https://doi.org/10.25073/2588-1159/vnuer.4120
}

postulates of metric space. Taxicab geometry is one of his works which is different from Euclidean geometry in terms of distance structure. Thus, if Euclidean geometry is a good model of the "natural world", Taxicab geometry is a better model of the artificial urban world that man has built, applied widely in real space [2, p110].

Our purpose of this paper is to design activities so that students can construct the concept of distance and realise practical applications of Taxicab geometry. At the same time, we propose research topics in line with students' capacity regarding several content areas of this geometry through project-based learning. Moreover, similarly to Euclide geometry, form the concept of the three types of conic section, through project-based learning, students can construct "conic section" in Taxicab distance and compare with three respective types of conic section in Euclidean geometry. 


\section{Research content}

In project-based learning and from didactics of mathematics perspective, "making learners active and setting them as the subjects do not reduce but, on the contrary, increase teachers' role and responsibility" $[3,4]$. Although students completely took initiative in implementing learning projects outside class contact time and space, teacher's responsibilities as the one who designed, authorised, controlled and institutionalised are manifested as follows:

Design: Teacher developed learning projects. Initially, some real situations were designed with the goal that students would approach the concept of Taxicab distance in the most familiar way and apply it to form similar concepts of stronger applicability in real life.

Authorise: In Euclidean geometry, conic section is defined based on distance. Using similar definitions, teacher oriented students to take initiative in developing and showing respective section in Taxicab geometry.

Control: Teacher monitored, checked and supported students in terms of knowledge, infrastructure, and psychological interventions when necessary during the process of learning project implementation.

Institutionalise: During group presentations on their products after implementing learning projects, teacher affirmed newly discovered knowledge, and unified individual knowledge into scientific one. Through this process, teacher guided students to apply and memorise knowledge [5, p3].

\subsection{Design learning projects}

In Euclidean geometry, students got to know points, and could identify straight lines, angles as well as distance between some geometrical objects. They were equipped with knowledge of the Cartesian coordinate system and could identify the distance between two points based on their coordinates. The distance between points $A\left(x_{1} ; y_{1}\right) ; B\left(x_{2} ; y_{2}\right)$ is the length of the line connecting them

$$
d_{E}(A, B)=\sqrt{\left(x_{1}-x_{2}\right)^{2}+\left(y_{1}-y_{2}\right)^{2}} .
$$

Taxicab geometry is quite similar to Euclidean geometry when the points, angles, Cartesian coordinate system, and coordinates of a point are specified in a similar manner as in Euclidean geometry. However, Taxicab distance is specified according to the following formula:

$$
\begin{gathered}
d_{T}(A, B)=\left|x_{1}-x_{2}\right|+\left|y_{1}-y_{2}\right| . \\
\text { Example if } A(1 ;-3), B(4 ; 1) \text { then } \\
d_{E}(A, B)=\sqrt{\left(x_{1}-x_{2}\right)^{2}+\left(y_{1}-y_{2}\right)^{2}}=\sqrt{3^{2}+4^{2}}=5 ; \\
d_{T}(A, B)=\left|x_{1}-x_{2}\right|+\left|y_{1}-y_{2}\right|=|1-4|+|-3-1|=7 .
\end{gathered}
$$

We designed learning projects and proposed steps to organise activities for students which would enable them to form concepts and understand the applications of Taxicab geometry as follows.

Step 1: Design activities for students to form the concept of distance in Taxicab geometry We set up a realistic situation: a city is divided into parallel streets with the same distance from each other in North-South and East-West directions. We can consider it as a coordinate plane $(O x y)$. An accident happens at point $X(1 ;-4)$. In the meantime, there are two squads of policemen at point $A(-2 ;-1)$ and $B(1 ; 1)$. Which squad has the shortest distance to the scene given that the city designs the streets parallel or perpendicular to each other in North-South and East-West directions? Obviously, the concept of distance in Euclidean geometry is no longer suitable in this situation.

We organised activities so that students could form a new concept of distance in the most natural manner. In order for students to 
take iniative in activities, we divided them into groups of five or six students.

Activity 1: Forming the concept of distance in Taxicabe geometry

Problem 1: Students were asked to study Bac Giang city's area. Use the city's tourist map or Google maps to identify the shortest distance between two particular locations. Prove that the route you have selected is the shortest.

Students used maps, computers connected with internet, Google maps and other materials to find information. Below is a photo of students using Google maps to take photo of partial Bac Giang city which shows main streets designed into horizontal and vertical axes.

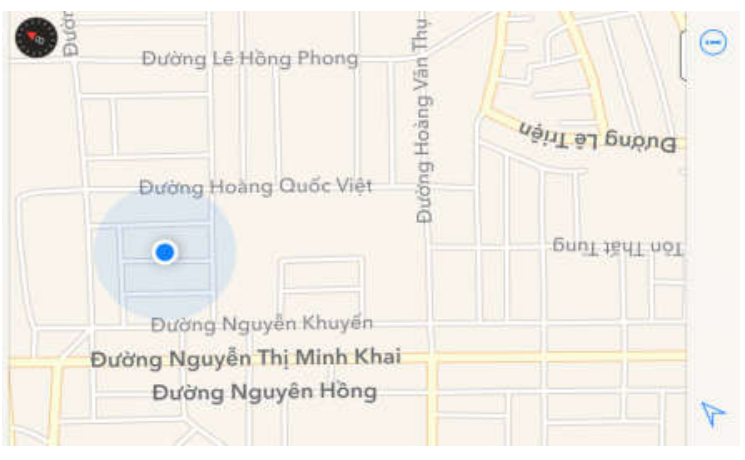

Figure 1. Part of Bac Giang city on street map.

Problem 2: Teacher provided particular locations and asked students to show the shortest distance between the two locations. Traffic routes allowed in the city are designed mainly based on vertical and horizontal axes. Hence, drivers need to follow the routes and are not allowed to go through people's houses.

Note down the routes to pick up and drop off three different passengers. Then identify the number of kilometers the driver has driven in order to bring passengers and move to the location to pick up the next passenger.

By means of images, students first realised that the shortest distance between the two locations is, in reality, not a straight line as in Euclidean geometry. Secondly, they noticed that there might be one or many answers for the shortest distance from one location to another. If a Cartesian coordinate system was incorporated into the city's map, we asked students to identify distance between locations in reality based on their coordinates. From the above activity, teacher asked students to find out the formula to calculate the shortest distance in real space which is the distance in Taxicab geometry.

In the Cartesian coordinate system $(O x y)$ there are two points $A\left(x_{1} ; y_{1}\right) ; B\left(x_{2} ; y_{2}\right)$.

Euclidean distance between the two is defined as:

$$
d_{E}(A ; B)=\sqrt{\left(x_{1}-x_{2}\right)^{2}+\left(y_{1}-y_{2}\right)^{2}}
$$

Distance in Taxicab geometry is defined as:

$$
\begin{aligned}
& d_{T}(A ; B)=\left|x_{1}-x_{2}\right|+\left|y_{1}-y_{2}\right| . \\
& \quad \text { If } A(-2 ;-1), B(1 ; 1) \text { and } C(4 ; 1) \text { then } \\
& d_{E}(B ; C)=d_{T}(B ; C)=3 ; d_{E}(A ; B)=\sqrt{13} ; d_{T}(A ; B)=5
\end{aligned}
$$

In order to move from point $A(-2 ;-1)$ to point $B(1 ; 1)$ using the shortest route, we cannot go straight from point $A$ to point $B$. One

\begin{tabular}{|c|c|c|c|}
\hline Route & Pick-up & Drop-off & $\begin{array}{l}\text { Distance }(\mathrm{km}) \\
\text { (Taxicab distance) }\end{array}$ \\
\hline \multicolumn{4}{|l|}{ Route 1} \\
\hline \multicolumn{4}{|l|}{ Route 2} \\
\hline \multicolumn{4}{|l|}{ Route 3} \\
\hline \multicolumn{4}{|l|}{ Route 4} \\
\hline \multicolumn{4}{|l|}{ Route 5} \\
\hline & & & Total number of $\mathrm{km}$ : \\
\hline
\end{tabular}
of the shortest route in reality is to move from point $A(-2 ;-1)$, pass point $E(-2 ; 1)$, and then reach point $B(1 ; 1)$, with the distance of 5 . 
Problem 3: Use Google maps to automatically identify the shortest route, then compare to the previous calculated result.

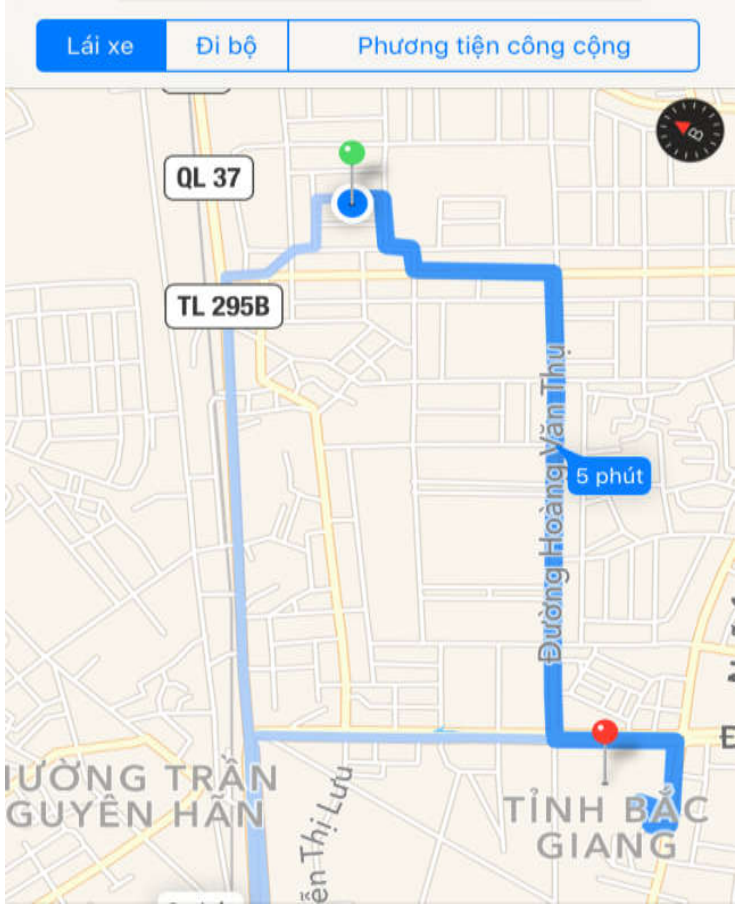

Figure 2. Google map show the shortest distance between the two locations.

\subsection{Teacher's authorisation of students' activities}

After designing activities to help students approach the new concept, by means of institutionalisation, teacher affirmed and developed a new definition of Taxicab distance for students. Our next goal was to instruct them to apply the knowledge by authorising them to continue finding the answer for the following problem.

Problem 4: Use Google maps to find the shortest distance between two locations

While using Google maps, students themselves realised that there was not only one answer for the shortest distance of each route. They noticed that the shortest distance was not identified as the only in Euclidean geometry and could fully explain it themselves based on the definition previously institutionalised by the teacher.

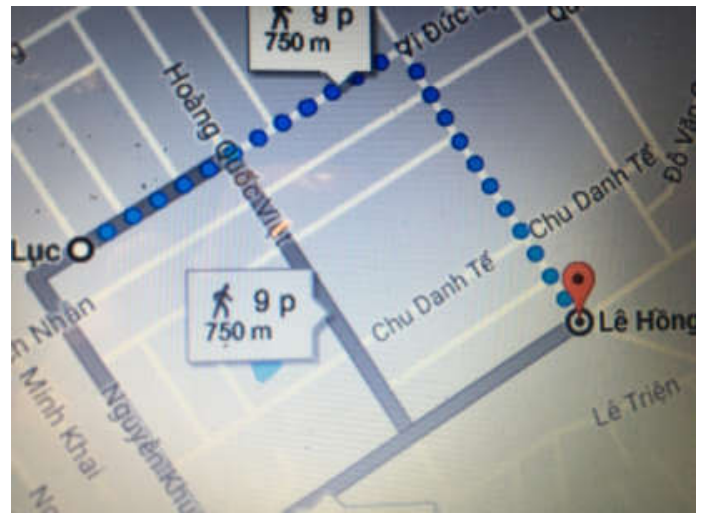

Figure 3. Different routes between the two locations.

Problem5: Using map scale to identify geographical distance or bird route between two locations (Euclidean distance). Compare this to the distance actually used by taxi and provide comments.

Comment: $d_{T}(A ; B) \geq d_{E}(A ; B)$.

Problem 6: If we know the Taxicab distance between two locations, can we identify the Euclidean distance between them?

Problem 7: A conference takes place at Bac Giang city's 3-2 Conference Centre (point $A(1 ; 1))$. In order to conveniently move by car, groups of delegates are arranged to stay at hotels which are $3 \mathrm{~km}$ or less from the centre. Use the city's tourist map or Google maps to find hotels that can satisfy the condition, given that the city's streets are planned as horizontal and vertical axis. Mark the locations of the hotels and provide comments on the marked locations.

Step 2: Design learning projects for students to apply the concept of distance in Taxicab geometry.

We proposed the topics for the two following learning projects.

Topic 1: "Applications of Taxicab geometry in reality". 


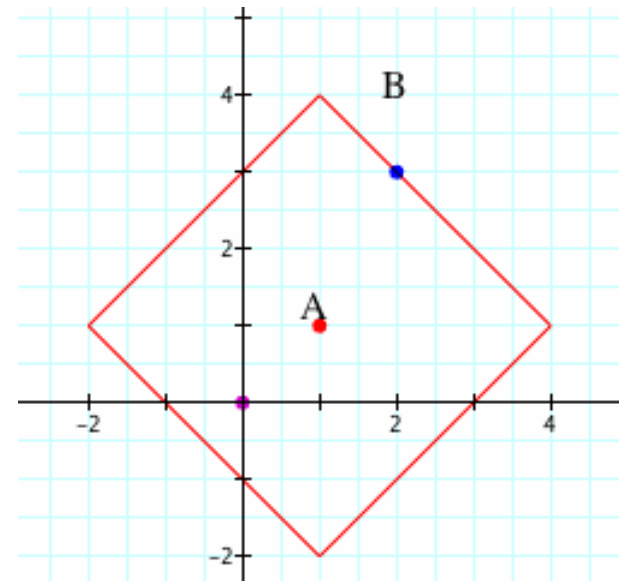

Figure 4. Points that are three blocks away from $A(1 ; 1)$.

Topic 2: "Similarities between Euclidean geometry and Taxicab geometry in forming the concept of the three types of conic section".

First, we let student groups select their project. If the selection was not balanced, we adjusted so that the number of groups doing each of the two projects was equal. Our purpose was letting students take initiative in handling the topics we proposed.

In order to make students implement projects, we first developed a set of lesson questions and noted down groups' solution under the questions.

1. An and Binh study at two universities at point $M(1 ; 1)$ and $N(8 ; 7)$ in the city. Where should they rent a house so that the distances from their house to the university are the same?

We need to identify a locus $I(x ; y)$ so that $d_{T}(I ; M)=d_{T}(I ; N) \Leftrightarrow|x-1|+|y-1|=|x-8|+|y-7|(*)$

There are 3 cases:

Case 1: $x<1$.

(i) If $\quad y<1 \quad$. Thus $\left.{ }^{*}\right) \Leftrightarrow 1-x+1-y=8-x+7-y \Leftrightarrow 13=0$ (no solution).

(ii) If $1 \leq y \leq 7 \quad$. Then $(*) \Leftrightarrow 1-x+y-1=8-x+7-y \Leftrightarrow y=\frac{15}{2}>7$ (no solution). (iii) If $y>7 \quad$ Hence

$\left(^{*}\right) \Leftrightarrow 1-x+y-1=8-x+y-7 \Leftrightarrow 0=1$

(no solution).

Case 2: $1 \leq x \leq 8$.

(i)

$$
\text { If } y<1 \quad . \quad \text { Then }
$$

$\left.{ }^{*}\right) \Leftrightarrow x-1+1-y=8-x+7-y \Leftrightarrow x=\frac{15}{2}$ (satify).

(ii) If $1 \leq y \leq 7$. Hence

(*) $\Leftrightarrow x-1+y-1=8-x+7-y \Leftrightarrow y=\frac{17}{2}-x$ (satify).

(iii) If $y>7 \quad$ We have

$(*) \Leftrightarrow x-1+y-1=8-x+y-7 \Leftrightarrow x=\frac{3}{2}$ (satify).

Case 3: $x>8$.

(i) If $y<1$ $\left.{ }^{*}\right) \Leftrightarrow x-1+1-y=x-8+7-y \Leftrightarrow-1=0$ (no solution).

(ii) If $\quad 1 \leq y \leq 7$. Thus

$(*) \Leftrightarrow x-1+y-1=x-8+7-y \Leftrightarrow y=\frac{1}{2}<7$ (no solution).

(iii) If $y>7$. We have $(*) \Leftrightarrow x-1+y-1=x-8+y-7 \Leftrightarrow 0=1$

(no solution).

Conclusion we have plotted the points and line so far that follow $d(M)=d(N)$ in Figure

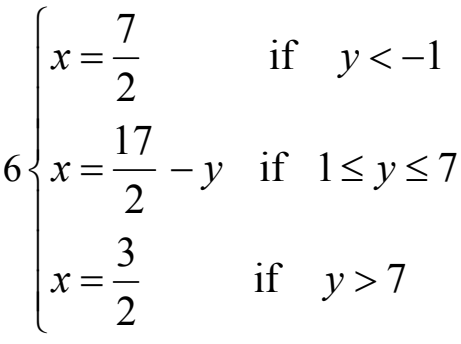

2. In the city, there are three hospitals at points $\mathrm{A}(-3 ; 1) ; \mathrm{B}(5 ; 1)$ and $\mathrm{C}(2 ;-6)$. Draw a boundary to divide the city into different areas so that each citizen can reach the closest hospital from their home. 


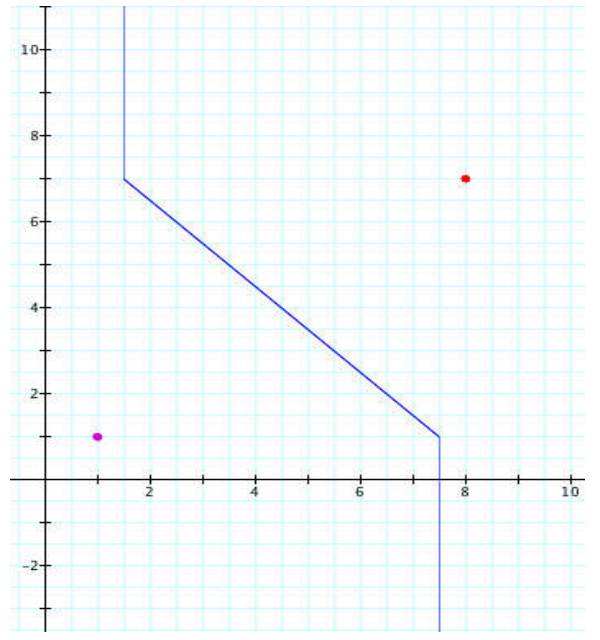

Figure 5. Plotted the points and line so far that follow $\mathrm{d}(\mathrm{M})=\mathrm{d}(\mathrm{N})$.

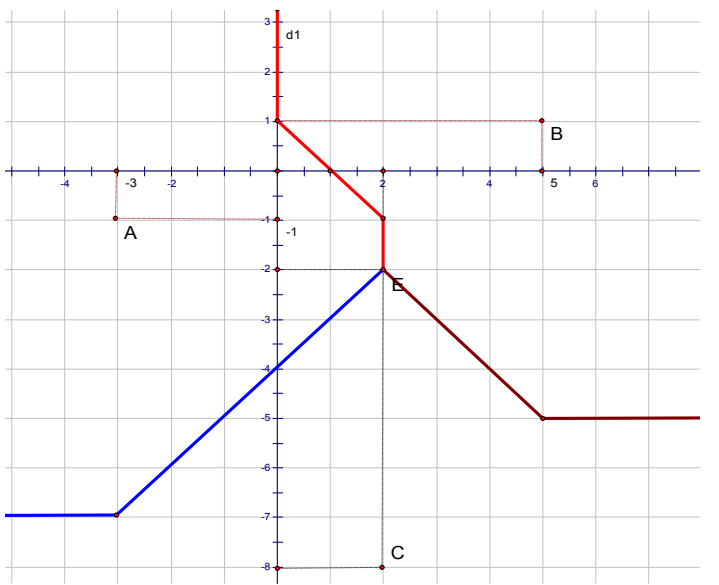

Figure 6 . City is divided by lines.

4. In a parallel route which is $2 \mathrm{~km}$ from the city's main route (route $\mathrm{y}=2$ ), there is a need to build a medical waste treatment plant. The three hosptials' waste is gathered at hospital A and carried away for treatment. Find out the location of the plant so that it is the closest to hospital A. However, for environmental protection, the plant should be at least $10 \mathrm{~km}$ away from the city centre.

5. a) Straight line $(\mathrm{AB})$ in Taxicab geometry is identified in a similar way as in Euclidean geometry. This is a line connecting points A and B. b) Give the definition of the distance from one point to a straight line in Euclidean geometry [6, p46].

6. Similar to Euclidean geometry, form the definition of the distance from one point to a straight line in Taxicab geometry. Tell the procedure to identify the distance.

Similar to definition of a circle in Euclidean geometry, define a cirlce in Taxicab distance and provide an example for illustration.

7. a) Repeat the definition of the three types of conic section in Euclidean geometry.

b) Similarly in Taxicab geometry, form the concept of the three types of conic section in Taxicab distance. Compare with three respective types of conic section in Euclidean geometry.

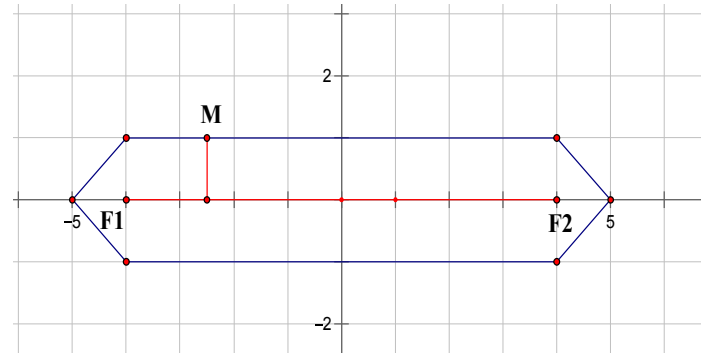

Figure 7. Ellipse in Taxicab Geometry.

\subsection{Control students' learning activities through their learning projects}

During their implementation of learning projects, we instructed and supported students in terms of infrustructure, time and when they faced difficulty.

Step 3: Design supporting references for students

- Contents in references: Eugene F.Karause (1986), Taxicab Geometry, an adventure in non-Euclidean geometry [1]; On the iso-taxicab trigonometry [2]; Taxicab Geometry: History and applications [6].

- Websites: dethi.violet, diendantoanhoc.net, math.vn, mathscope, mathlink,...

- Learning project monitoring book

- Group work division form: 


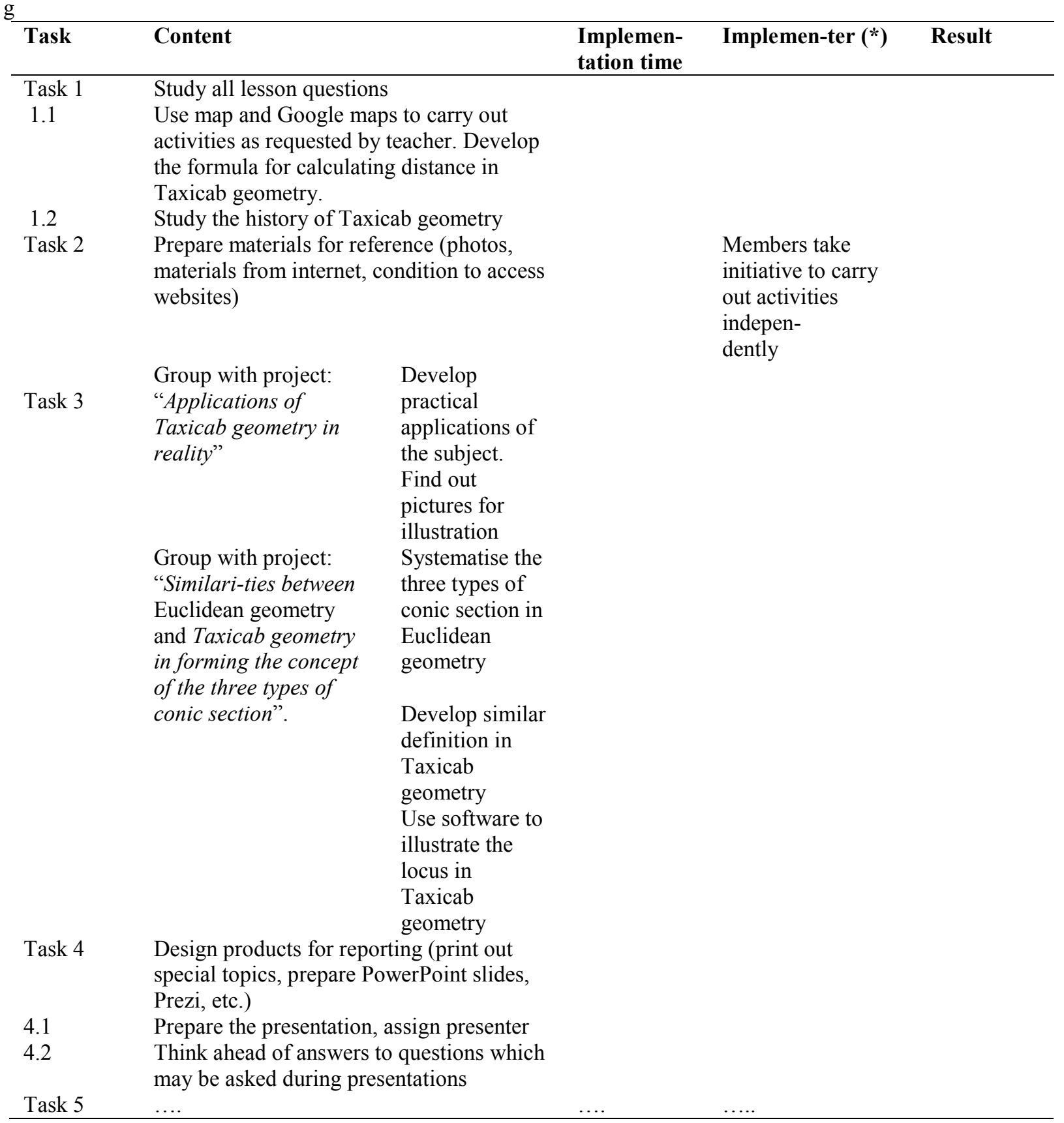

Figure 8. Group work division form.

\subsection{Institutionalise knowledge for students}

Step 4. Organise for students to implement learning projects and present their product in front of the class

Teacher set up time and invited other colleagues to attend student groups' presentations according to the projects previously selected. During this step in learning projects, teacher was responsible for affirming newly discovered knowledge and at the same time unified individual and separate knowledge in group products after project completion into 
scientific knowledge. In addition, teacher and student groups evaluated their products [7].

\section{Result of students' implementation}

During and after students' implementation of learning projects, we observed that:

- For the topic Similarities between Euclidean geometry and Taxicab geometry in forming the concept of the three types of conic section, students took initiative to investigate it using software for drawing illustrations.

- Students took initiative in learning. They were enthusiastic and active in studying to develop products for their projects: they were active and took initiative in choosing learning projects and solving content questions, and dividing work within their groups in line with each member's capacity. They also took initiative in terms of group discussion time. They were active in designing slides to report on their products and finding images for illustration.

- Presentation: they were active in presentation rehearsal to give a smooth talk in front of the class.

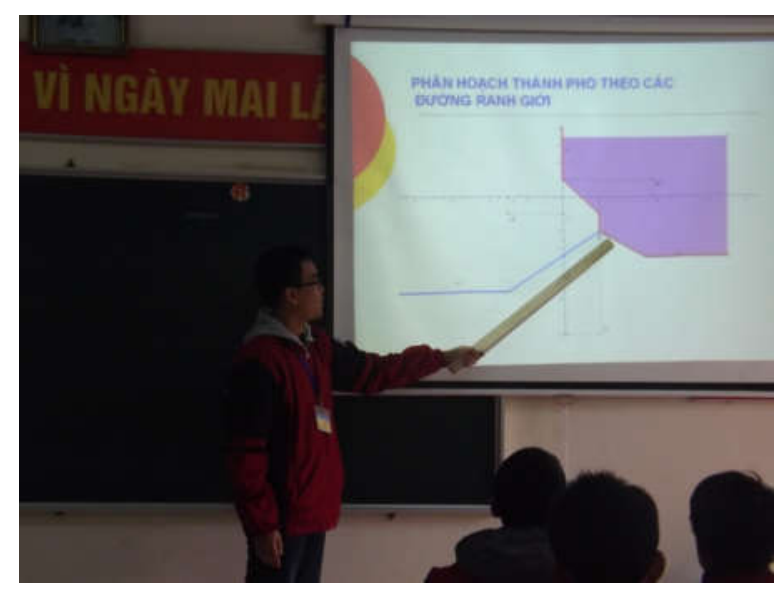

Figure 9. Presentation of students.

- Students brought into play their creativity: they took initiative in developing an observable model to illustrate Taxicab distance and its applications in reality. Similarly, they formed a new concept of the three types of conic section in Taxicab geometry, a very new concept to them, and drew illustrations using software.

- Students read the materials themselves and presented on the direction to expand the project on a new distance (using new metric in non-Euclidean geometry called Large distance) $d_{L}(A ; B)=\max \left\{\left|x_{A}-x_{B}\right| ;\left|y_{A}-y_{B}\right|\right\}[1]$

Through this process, we could observe students' seriousness in investigation in learning projects, their creativity, interest and their learning with a clear purpose.

\section{Conclusion}

Taxicab geometry is a type of nonEuclidean geometry which has a close structure to Euclidean geometry and is in line with high school students' knowledge reception. In order to help them approach this new concept, we designed learning projects and organised activities for students to study and investigate from the didactics of mathematics perspective. Through projects - based learning, students could form the concept of distance in Taxicab geometry and clearly realise its applications. They could form and draw illustrations of concepts similar to the three types of conic section. Students were trained up the skill to work independently and in groups, brought into play the capacity to study and solve problems themselves, and had opportunities to present what they had learnt and received from teacher as well as peers' feedback.

\section{References}

[1] Eugene F.Karause, Taxicab Geometry, an adventure in non-Euclidean Geometry, Dover Publications, Inc. NewYork (1986) .

[2] Ada T. and Kocayusufoglu On the iso-taxicab trigonometry, PRIMUS, 22(2): 108 - 133, ISSN 1051-1970 (2012) 108.

[3] Chau Le Thi Hoai, Changes brought about by didactics in teacher training in Vietnam (Những 
thay đổi mà didactic có thể mang lại cho việc đào tạo giáo viên ở Việt Nam), Presentation at the 1 st Conference on didactics - mathematics teaching approach (Ho Chi Minh University of Education, June 17-18th, 2005).

[4] Fenandez, Paz Didactic Innovative Proposal for Mathematic learning at the University by the Blended Model, Social and Behavioral Sciences, 7 October 2014, Vol.152 (2014) 796.

[5] Kim Nguyen Ba, Research into mathematics teaching and mathematics pedagogical reform (Nghiên cứu dạy học toán và đổi mới phương pháp dạy học toán), Presentation at the 1 st
Conference on didactics - mathematics teaching approach (Ho Chi Minh University of Education, June 17-18th, 2005).

[6] Chip Reinhardt, Taxicab Geometry: History and applications, The Montana Mathematics Enthusiast, ISSN 1551-3440, Vol 2, no.1 (2005) 38.

[7] Cuong Tran Viet, Organising project-based learning in teaching mathematics for senior high school students (Tổ chức dạy học theo dự án trong dạy học môn Toán cho học sinh trung học phổ thông), Journal of Education, Issue 325 (No 1, January 2014) 44.

\title{
Chuyển đổi Didactic tổ chức dự án khoảng cách và ứng dụng trong hình học Taxicab cho học sinh chuyên toán
}

\author{
Chu Cẩm Thơ ${ }^{1}$, Trần Thị Hà Phương ${ }^{2}$ \\ ${ }^{1}$ Viện Khoa họ giáo dục Việt Nam \\ ${ }^{2}$ Trường THPT Chuyên Bắc Giang, đương Hoàng Văn Thụ, thành phố Bắc Giang, tỉnh Bắc Giang
}

Tóm tắt: Những năm đầu thế kỷ 20, Minkowski (1864-1909) đã đưa ra ý tưởng về một metric mới, một trong nhiều metric của hình học phi - Ơclit mà ông đã thiết lập, đặt nền móng đầu tiên cho hình học Taxicab. Mục đích của chúng tôi là thiết kế các hoạt động để học sinh có thể xây dựng được khái niệm khoảng cách và các vận dụng thực tế của hình học Taxicab thông qua học tập theo dự án.

Từ khóa: Chuyển đổi Didactic, Hình học Taxicab, học tập theo dự án. 